JSCM T

Journal of Sustainable Construction

Materials and Technologies

J. Sustain. Construct. Mater. Technol. 2(1) (2017) 79-82
Journal of Sustainable Construction Materials and Technologies

http://www.eds.yildiz.edu.tr/jscmt

\title{
Paper-tubes as a building material
}

\author{
Anand Shaha,*, Sapan Hirparab \\ ${ }^{a}$ B.Tech (Hons.), Faculty of Technology, CEPT University, Ahmedabad - 380009, India \\ ${ }^{b}$ B.Arch, Faculty of Architecture, CEPT University, Ahmedabad - 380009, India
}

Received September 6, 2016; accepted June 19, 2017

\begin{abstract}
There has always been a need for recyclable materials in the construction industry. Taking this fact into consideration an exploration using paper tubes and medium density fiber-board (M.D.F) as construction materials was ventured. In order to understand these materials, a temporary space frame was made. The paper describes in detail the entire process of making the space frame. Issues related to shape and size of the structure, connection detail and its material, wind forces etc., which occur frequently during the making of such structures are discussed in depth. At last the strengths, weaknesses, and scope of paper tubes as a building construction material in coming future have been discussed.
\end{abstract}

Keywords: Paper tube; medium density fibre-board; space-frame; sustainable; cable

\section{Introduction}

The 21st century has contributed hugely to the evolution of construction materials, which should be credited mainly to arise of sustainable construction due to rising environmental concerns. "Paper is evolved wood," writes Shigeru ban, the Pritzker-winning Japanese architect in his book [1]. It is astonishing to see how he uses sustainable paper-tubes made out of recycled paper as construction material. Ban beautifully incorporates lightweight designs using these sustainable paper-tubes into relief construction and temporary architecture as discussed in [2]. This arouses inquisitiveness to know how construction can be made possible with such a material which is extremely light weight, delicate and vulnerable to damages so easily.

In order to understand a material, getting hands on experience on it is as important as reading literature related to it. Therefore, to understand its physical characteristics, workability and feasibility as a material, a space frame (as shown in Fig. 1) was designed. It was an exploration of sustainable architecture which resulted into an engineered three-dimensional frame sculpture.

\footnotetext{
* Corresponding author.

E-mail address: anand.shah.sbst12@cept.ac.in (A.Shah)

https://doi.org/10.29187/jscmt.2018.10
} 

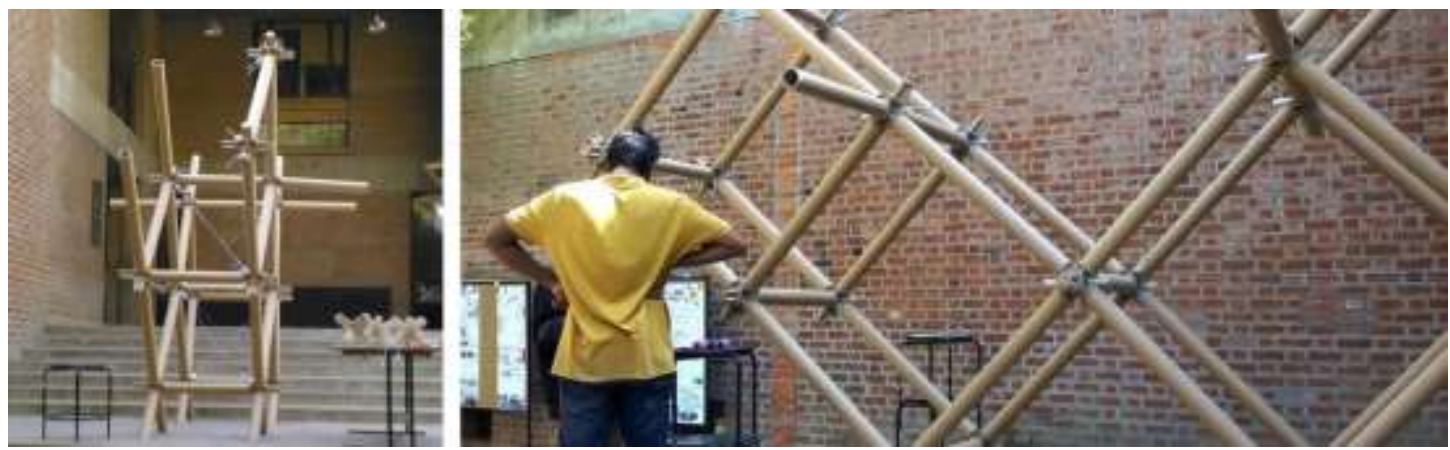

Fig. 1. Paper-tube space frame.

\section{Methodology}

\subsection{Design process and inspirations}

A cuboid acted as the fundamental module for space frame. As working with a material like paper-tube was an experiment, a very basic design in which cuboid incorporated as a very simple and stable element was used. Further articulation and resolving joints resulted in a simplified space frame. Paper-tubes of $81 \mathrm{~mm}$ in diameter and $20 \mathrm{~mm}$ thick were used as frame members.

The design of the Space frame was somewhat inspired from Shigeru ban's early works of "Odawara east gate" (1990, Japan) and "Library of Poet" (1991, Japan), where he uses paper-tube as frame members for truss columns as mentioned at [3]. "The Odawara east gate" project uses $15 \mathrm{~mm}$ and $12.5 \mathrm{~mm}$ thick post-tensioned paper-tubes as frame members where post-tensioning is done using steel rods and paper-tubes are connected via steel angle joints. Each frame is diagonally braced using steel rods [1]. While in case of "Library of Poet", $12.7 \mathrm{~mm}$ thick paper-tubes having $100 \mathrm{~mm}$ in diameter were used as mentioned in [4] and [1]. All the tubes are post tensioned, every frame is diagonally braced, but here timber pieces of $1.5 \mathrm{in}^{2}$ are used as connecting members instead of steel angles as done in "Odawara east gate" project.

Post-tensioned rods were not used for the space frame because the structure did not require them and they would thus unnecessarily add to its dead weight. MDF jigsaw plugs were used as connecting members, indifferent to "Odawara east gate" and "Library of poet" were steel angles and timber joints were used as connecting members respectively. The main reason for it was high cost of timber and high dead weight for steel joints.

\subsection{Fabricating members and understanding paper-tubes.}

During the fabrication, a series of steps like cutting, drilling, grinding etc. of paper-tubes were explored (as shown in Fig. 2). This gave an insight into the structural composition of paper-tube at a macro level.
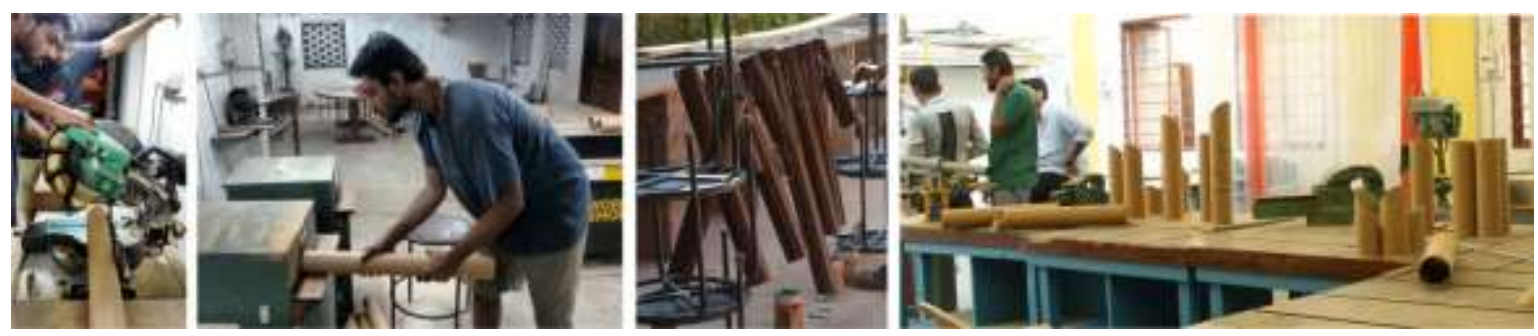

Fig. 2. Hands on work with paper-tube: cutting, grinding and waterproofing 


\subsection{Designing and fabricating connections.}

Plugs made out of M.D.F. (medium density fiber) boards (as shown in Fig. 3) were used in order to connect the paper-tube members. The main reason behind using Medium density fiber as connecting units was due to its light weight, cheap cost and most importantly being coherent to paper-tube in terms of its structural composition and material. M.D.F. jigsaws were mass produced using a C.N.C. router machine. Joining of this 2- dimensional M.D.F. jigsaw pieces resulted into a 3- dimensional plug. Circular sockets having a diameter equal to the inner diameter of paper-tubes were plugged with the M.D.F. joints. Sockets were provided for a proper contact between the tubes and the joints so that a strong connection through surface contact can be established. Interlocked M.D.F. plugs worked very efficiently, because interlocking enhanced under the action of compressive forces.
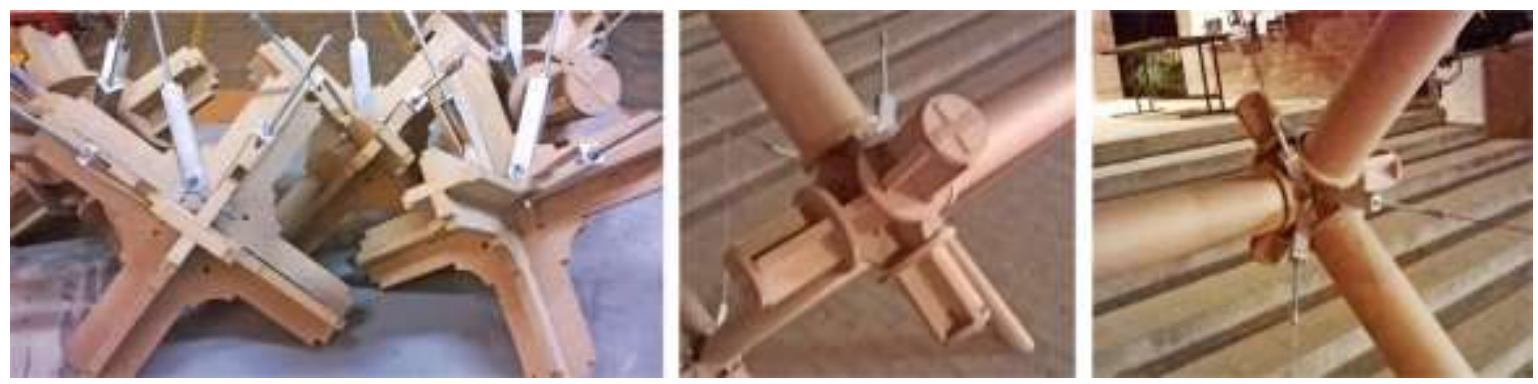

Fig. 3. Medium density fibre-boards acting as junction connection for paper-tube members

Being very light weight, the frame needed some kind of lateral bracing in order to resist wind forces. Therefore, with reason to provide lateral stability, bracing using $2 \mathrm{~mm}$ diameter steel cables was done. Instead of going for readymade cable joinery systems, an assembled system was prepared using various hardware. An excessive market survey gave us an overview regarding various available hardware. This resulted into a cheap and effective connection detail (as described in Fig. 4).
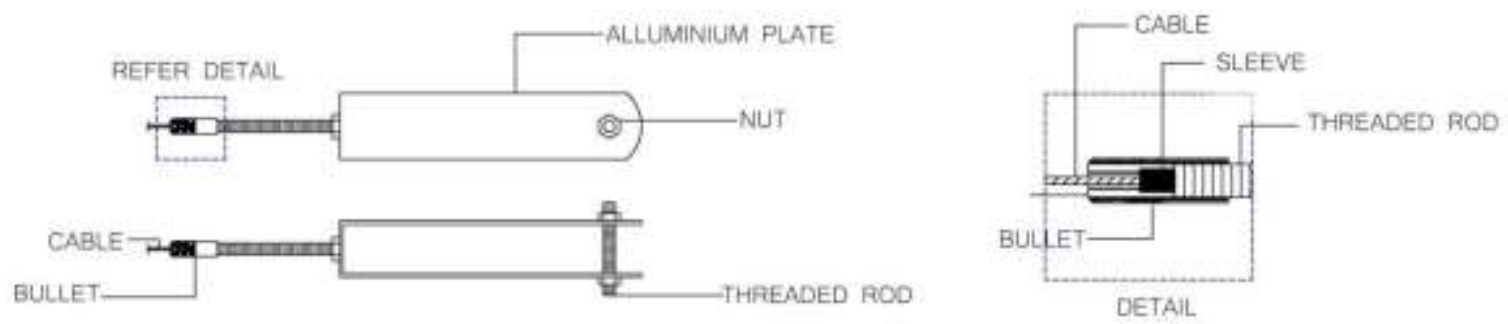

Fig. 4. Connection details for cable bracing

The cable detail consisted of threaded road, bullet, sleeve, and aluminium section. Aluminium section is connected to MDF plug by nut-threaded rod system. Cable is inserted into metal sleeve and pushed into the bullet, threaded rod locks the bullet from one end and the bullet itself due to its configuration prevents the cable to sleek out from the other end (Refer detail drawing in Fig. 4). But the cable connection system has two disadvantages, under large tensile forces the connection system between MDF plug and threaded rod may fail in block shear and the cable may slack out in case of excessive tension forces. But over here i.e. for the space frame the magnitude of forces are quite small and therefore this design is appropriate and works well. 
The entire frame was taken out of workspace and put in open so that every student and faculty can have a look at it and can debate, as well as discuss their views about it. After a week, the structure was disassembled and put back into our workshop space, so that it can be re-used in one way or the other. The main aim was to understand material properties of paper-tube by constructing something which is aesthetically pleasant as well as structurally sound. Moreover, as the budget was a big constraint, even that was to be kept in mind.

\section{Discussions}

As paper-tube is not a mainstream material, problems from governing body related to construction permit may arise. For "Odwara east gate", a special permit to build this project was required, but due to time crunch, construction period did not allow enough time for taking proper permissions. Therefore, the building turned out to be a temporary structure made for a duration of 6 months [4]. Being very delicate in nature, structural designers should take a considerable safety factor while designing them. After designing the structure, proper laboratory testing of tube members and their joints is required. The members and the joints should be tested according to the forces acting on it in simulation model [5]. Waterproofing and fireproofing as per government requirements is to be done, to ensure safety for residents. In case of Paper Dome (1998, Japan) urethane - resin diluted with thinner was used as waterproofing agent, and in case of Japan Pavilion (2000, Germany) the paper tubes were made to clear B-2 grade fireproofing requirements of Germany [6].

\section{Conclusion}

If properly designed and executed, paper-tube structures can be very effective for places where earthquakes occur frequently. As paper-tubes are lightweight, structures made out of it will pose less danger to its residents, in case of collapse during an earthquake. Permanent structures have been made using paper-tubes but their life time is a point of question. Shigeru Ban very intelligently says "I wonder, what a permanent is and what a temporary building is? Even a building made in paper can be permanent as long as people love it. Even a concrete building can be very temporary if that is made to make money" [7].

\section{References}

S. Ban, Shigeru Ban, First ed., vol. 1, E. Bell, Ed., New York, New York: Princeton Architectural Press, 2001.

E. Charlesworth, Humanitarian architecture: fifteen stories of architects working after disaster, New York: Routledge, 2014.

S. Ban, "shigeru ban architects," shigeru ban architects, 1991. [Online]. Available: http://www.shigerubanarchitects.com/works.html.

P. Jodidio, Shigeru Ban, Complete Works 1985-2010, P. Jodidio, Ed., Hohenzollernring 53, 50672 Köln: Taschen GmbH; Box Mul edition, 2010.

T. D. G. L. C. Bank, Nonconventional and Vernacular Construction Materials - Characterisation, Properties and Applications, 1st ed., B. S. K.A. Harries, Ed., New York: Woodhead Publishing Series in Civil and Structural Engineering, 2016, p. 514.

M. McQuid, Shigeru Ban, Phaidon Press Limitied, 2003.

S. Ban, Shigeru Ban : Emergency shelters made from paper [video], Tokyo, 2013. 